\title{
Genotypic diversity and grazer identity interactively influence seagrass and grazer biomass
}

\author{
A. Randall Hughes ${ }^{1, *}$, Rebecca J. Best ${ }^{2}$, John J. Stachowicz ${ }^{2}$ \\ ${ }^{1}$ Coastal and Marine Laboratory, Florida State University, 3618 Highway 98, St. Teresa, Florida 32358, USA \\ ${ }^{2}$ Evolution and Ecology, University of California Davis, One Shields Avenue, Davis, California 95616, USA
}

\begin{abstract}
Despite experimental evidence for effects of primary producer diversity and consumer species diversity on population and community processes, little is known about how diversity at these multiple trophic levels may interact. We conducted a mesocosm experiment to examine the independent and interactive effects of seagrass Zostera marina genotypic diversity and grazer species diversity on seagrass, epiphyte, and grazer responses. There were no interactions between seagrass genotypic diversity and grazer species diversity, per se; however, the effects of seagrass genotypic diversity on both seagrass and grazer biomass depended on grazer species identity. In particular, seagrass biomass was higher in polyculture than in monoculture, but only when the sea hare Phyllaplysia taylori was the only grazer present. This enhanced growth was due to complementarity among genotypes in the presence of $P$. taylori. Seagrass genotypic diversity effects on grazer biomass and fecundity were small and/or idiosyncratic, yet grazer species composition had a large impact on grazer reproductive effort. Only grazer species identity, and not seagrass genotypic diversity or grazer species diversity, affected epiphyte biomass, consistent with other findings of the importance of species identity. Our results confirm the effects of seagrass genetic diversity on the plant itself as well as the grazer species that utilize it for both food and habitat. Furthermore, they emphasize the importance of grazers for controlling epiphyte and seagrass biomass.
\end{abstract}

KEY WORDS: Biodiversity-ecosystem function · Eelgrass $\cdot$ Epiphytes $\cdot$ Genetic diversity $\cdot$ Herbivory Zostera marina

Resale or republication not permitted without written consent of the publisher

\section{INTRODUCTION}

With increasing losses in species numbers and abundance, understanding the ecological effects of biodiversity has become a central theme in ecology. Although there are certainly exceptions, experimental increases in species diversity tend to have an overall positive effect on ecosystem processes like productivity (Balvanera et al. 2006, Cardinale et al. 2007). In addition, a growing body of evidence points to the importance of diversity within species (i.e. genetic diversity) for population-, community-, and ecosystemlevel processes (Hughes et al. 2008). The majority of biodiversity studies have manipulated species or genetic diversity at the plant/producer level, revealing effects on producer productivity, nutrient cycling, and community structure (Balvanera et al. 2006, Hughes et al. 2008). In particular, genetic diversity can have strong effects on the diversity, abundance, and distribution of species associated with habitat-forming plants in marine and terrestrial systems (Hughes \& Stachowicz 2004, Reusch et al. 2005, Crutsinger et al. 2006, Johnson et al. 2006, Crawford et al. 2007), analogous to the effects of producer species diversity (Balvanera et al. 2006). However, in most, if not all, of these studies only genetic diversity was manipulated, and thus we have little sense of the strength of the effects of genotypic diversity relative to other factors (Hughes \& Stachowicz 2009).

Consumer presence or abundance can also have strong effects on primary producer diversity (Lubchenco 1978) and biomass (Hairston et al. 1960, 
Schmitz et al. 2000). Although not as commonly manipulated as either consumer presence or producer diversity, consumer diversity and trophic level diversity (i.e. the number of trophic levels) can also be important for community- and ecosystem-level processes (Duffy et al. 2007). For example, predator diversity in kelp communities decreases foraging of intermediate consumers and results in increased kelp biomass via a trophic cascade (Byrnes et al. 2006). Further, the addition of a trophic level can alter the outcome of diversity manipulations at a different trophic level: increased seagrass grazer diversity led to increased grazer biomass and seagrass biomass only when predators were present (Duffy et al. 2005).

Although there have been significant advances in our understanding of the unidirectional impacts of diversity at one trophic level on another, we have relatively little information regarding how diversity at multiple trophic levels interacts to influence population and community processes (but see Fox 2004, Aquilino et al. 2005, Gamfeldt et al. 2005, Bruno et al. 2008, Douglass et al. 2008). The evidence to date suggests that, although not universal (e.g. Aquilino et al. 2005), significant interactions between levels of diversity can occur. For example, prey richness and consumer richness interactively affected total community biomass in a marine microbial system: differences among levels of prey diversity were only apparent at the highest consumer diversity (Gamfeldt et al. 2005). Similarly, increased herbivore diversity decreased macroalgal growth in experimental mesocosms, and this difference was exacerbated at higher algal diversity because of positive effects of algal diversity on growth (Bruno et al. 2008).

Despite the relative scarcity of experimental manipulations, we expect that interactions between changing diversity of producers and consumers are widespread for 2 reasons: (1) changes in biomass as a result of changing producer diversity can affect the quality and quantity of food or shelter for higher trophic levels (Balvanera et al. 2006), and (2) animals can affect the abundance and diversity of plants through many pathways (Schmitz et al. 2000, Bruno \& Cardinale 2008). Given the parallels between ecological effects of species and genetic diversity (Hughes et al. 2008), similar interactions may occur between genetic diversity at one trophic level and species diversity at another. To examine these potential interactions, we simultaneously manipulated seagrass (Zostera marina) genotypic diversity and invertebrate grazer species diversity in a factorial replacement-series design in experimental mesocosms and examined their independent and interactive effects on (1) producer (seagrass and epiphyte) biomass and (2) grazer biomass and fecundity.

\section{MATERIALS AND METHODS}

Study system. Seagrasses, marine angiosperms that form critical habitat in coastal ecosystems worldwide, provide an ideal system for examining interactions between genetic and species diversity. First, seagrass genotypic diversity influences the productivity of the seagrass itself, as well as the community of organisms that depend on it. For example, seagrass genotypic diversity has positive effects on seagrass biomass, particularly in response to disturbances such as grazing (Hughes \& Stachowicz 2004, Reusch et al. 2005). Seagrass genotypic diversity can also lead to increased species abundance and diversity of the community of invertebrates closely associated with seagrass habitat (Hughes \& Stachowicz 2004, Reusch et al. 2005).

In addition to the effects of seagrass genotypic diversity on seagrass and community responses, grazer species identity and diversity can have strong impacts on the biomass of seagrass and the algal epiphytes that grow on the seagrass (Duffy et al. 2001, Duffy et al. 2003, Duffy et al. 2005). As grazer species vary in their preference for and ability to consume algal epiphytes or seagrasses (Duffy \& Harvilicz 2001), the intensity of direct herbivory on seagrass versus the removal of epiphytes may vary between grazer monocultures and mixtures. The type and intensity of herbivory may then affect the rate at which seagrass genotypes grow and compete with each other and with epiphytes.

In this study, we utilized 6 genetically distinct clones of Zostera marina (hereafter Zostera) that exhibit considerable morphological and physiological variation when grown in a common environment (Hughes et al. 2009). This variation could contribute to effects of genotypic diversity on associated species through a variety of mechanisms, including greater food availability due to increased productivity in genetically diverse mixtures, lower susceptibility to predation due to enhanced habitat complexity in mixtures, or greater fitness due to the more diverse diet available in mixtures (Stachowicz et al. 2007). We also included 3 of the most commonly found grazers in seagrass beds in Bodega Harbor, California (R. Hughes unpubl. data): the isopod Idotea resecata (hereafter, Idotea), the sea hare Phyllaplysia taylori (hereafter, Phyllaplysia), and the gastropods Lacuna/Lirularia spp. (hereafter, Lacuna). These grazer species differ in feeding strategies: whereas they all prefer to consume epiphytic algae, both Idotea and Lacuna will also consume seagrass (Williams \& Ruckelshaus 1993, R. Hughes unpubl. data). Due to the important role of epiphytes in this food web, and because of their contribution to seagrass declines (Hughes et al. 2004, Orth et al. 2006), we quantified epiphyte biomass in addition to seagrass and grazer responses. 
Experimental set-up. We conducted a mesocosm experiment to examine the independent and interactive effects of Zostera genotypic diversity (2 levels: monoculture and polyculture) and invertebrate mesograzer diversity (2 levels: 1 species and 3 species) on epiphyte biomass, Zostera biomass and shoot density, and grazer biomass and reproductive effort. The 6 genetically distinct clones of Zostera (genotypes red, green, yellow, orange, purple, and blue from Hughes et al. 2009) were taken from stock propagated in separate outdoor mesocosms at Bodega Marine Laboratories since June 2004 (see Hughes et al. 2009 for more detail regarding propagation methods). We planted all experimental mesocosms with 4 Zostera terminal shoots: in genotypic monocultures all 4 shoots were from the same genotype, with 6 monocultures in total (1 for each genotype); in genotypic polycultures each terminal shoot was from 1 of 4 different genotypes, with 6 randomly generated unique 4 -genotype combinations from all possible combinations of the 6 genotypes planted in monoculture. Thus, there were 12 genotypic identity treatments ( 6 unique monocultures and 6 unique polycultures).

We tested 5 different grazer treatments in all, including a no grazer control, 3 single species treatments (Phyllaplysia only, Idotea only, and Lacuna only), and a 3-species treatment. To account for differences in grazer biomass as well as variation in natural densities in the field, the single species grazer treatments received either 9 individuals of Idotea, 9 individuals of Phyllaplysia, or 18 snails (9 Lacuna/9 Lirularia). These numbers are within the range observed in natural Zostera beds in our study area (R. Hughes unpubl. data). We utilized a substitutive design (i.e. the 3-species treatment contained 3 Idotea, 3 Phyllaplysia, and 3 Lacuna/3 Lirularia). Although this design can confound diversity with reduced intraspecific density, a combined design that also controlled for intraspecific density was not possible because of limits on the number of mesocosms available. As we were interested in the effects of grazer diversity or seagrass genotypic diversity on grazer reproductive effort, we included 5 and 2 brooding Idotea in the 1-species and 3-species treatments, respectively. We also removed all existing Phyllaplysia and Lacuna egg cases prior to the start of the experiment.

We crossed the 2 genotypic diversity treatments (represented by 6 monocultures and 6 polycultures, as described above) with the 5 grazer treatments $(0,1$, and 3 species) to yield 60 experimental replicates. These treatments were randomly assigned to 60 individual 22.71 flow-through outdoor mesocosms at Bodega Marine Laboratories $\left(38^{\circ} 19.110^{\prime} \mathrm{N} \quad 123^{\circ} 04.294^{\prime} \mathrm{W}\right)$. There was only 1 replicate of each grazer identity treatment for each particular seagrass monoculture or poly- culture; replication was achieved across rather than within genotypic monoculture and polyculture combinations. The 60 mesocosms were placed in a fixed array of 15 larger tanks (i.e. 4 mesocosms per tank). Due to expected variation in environmental conditions (light, temperature) in our experimental array, we divided the tanks into 3 blocks of 20 mesocosms each.

In May 2008, we added 21 of sieved field-collected sediment to each mesocosm and then transplanted 4 Zostera terminal shoots clipped to a standard shoot $(30 \mathrm{~cm})$ and rhizome $(2.5 \mathrm{~cm})$ length. We allowed epiphytes to accumulate for $5 \mathrm{~d}$ before adding invertebrate grazers to the tanks. At the end of $12 \mathrm{wk}$, we quantified the epiphytic algal biomass on Zostera shoots, seagrass shoot density and biomass (aboveground, belowground, and total), grazer density and biomass, and per capita grazer reproductive effort (number of juvenile Idotea or number of Phyllaplysia and Lacuna egg sacs). Zostera terminal shoots were removed from the sediment while keeping rhizomes intact, allowing us to assign new vegetative growth to the appropriate original terminal shoot.

Statistical analyses. We conducted 2 types of statistical analyses of our data. In the first, we examined whether genotypic diversity and grazer diversity independently or interactively affected (1) epiphyte or seagrass responses or (2) grazer responses using a multivariate analysis of variance (MANOVA) on all response variables with block, genotypic diversity, grazer treatment, and all possible interactions as fixed factors. As the MANOVA was significant, we then conducted separate analyses of variance (ANOVA) on individual response variables. We tested for effects of grazer diversity using planned independent contrasts to compare the 1-species grazer treatments to the 3-species grazer treatment. The proportion of variance explained by each factor was calculated by $\omega^{2}$ (Olejnik \& Algina 2003).

There was a significant interaction between grazer identity and genotypic diversity on seagrass biomass, with genotypic polycultures out-performing genotypic monocultures in the Phyllaplysia treatment (see 'Results'). To examine this interaction further, we first compared the observed biomass of each unique polyculture treatment $(\mathrm{N}=6)$ in the presence of Phyllaplysia to that expected based on the performance of each of the component genotypes in monoculture with Phyllaplysia. Expected values were calculated by (1) dividing each monoculture yield by 4 (the initial number of transplants) to generate an average per transplant monoculture yield for each genotype, and (2) summing these values for each genotype in a given polyculture treatment. In addition to comparing observed and expected values, we also calculated the total biodiversity effect and partitioned it among dominance and complementarity mechanisms according to 
standard methods (Fox 2005). The strength of traitindependent complementarity (TIC) varied widely among individual polycultures (see Results). We hypothesized that this variation may be due to differences in the degree of trait differentiation among individual genotypes in particular polyculture combinations. Using variation in monoculture biomass among the genotypes in a polyculture as a proxy for trait differentiation, we tested whether there was a relationship between the strength of TIC and the variance in monoculture biomass of the component genotypes.

In the second set of analyses, we evaluated the effects of genotypic and grazer diversity on grazer reproductive effort by conducting separate ANOVAs for each grazer species with block, seagrass genotypic diversity, grazer diversity (single species vs. all species), and all possible interactions as fixed factors. Statistical significance of differences among treatment means was assessed using Tukey's post-hoc tests. All analyses were conducted using JMP 5.0.

\section{RESULTS}

\section{Seagrass and epiphyte response}

Seagrass genotypic diversity and grazer species identity interactively affected total seagrass biomass (Fig. 1a; see Table 1 for full statistics), primarily due to effects on aboveground biomass (Table 1). Phyllaplysia treatments resulted in higher seagrass biomass (Fig. 1a) and belowground biomass (Fig. 2) than any of the other grazer treatments. Differences in epiphyte biomass alone could not explain these effects: epiphyte biomass was comparably reduced in the presence of Phyllaplysia, Idotea, and the grazer polyculture (Fig. 1b), yet only the Phyllaplysia treatments yielded higher seagrass biomass. Despite significant differences among single-species grazer treatments, grazer species diversity did not affect plant biomass (Table 1), as the effects of combinations of grazers did not differ from that of the average grazer monoculture.

In addition to an effect of grazer identity on seagrass biomass, there was an interaction between grazer identity and genotypic diversity: genotypic polycultures with Phyllaplysia had higher biomass than any other treatment combination (Fig. 1a) despite equivalent reductions in epiphyte biomass in the Phyllaplysia, Idotea, and grazer polyculture treatments (Fig. 1b). Actual polyculture seagrass biomass (mean $[\mathrm{SE}]=8.36$ [0.51] g) was higher than the calculated expected value (mean $[\mathrm{SE}]=6.28$ [0.53] $g$; $t$-test $p=0.02$; Fig. $3 a$ ) and also exceeded the biomass of the best-performing genotypic monoculture (7.95 g).
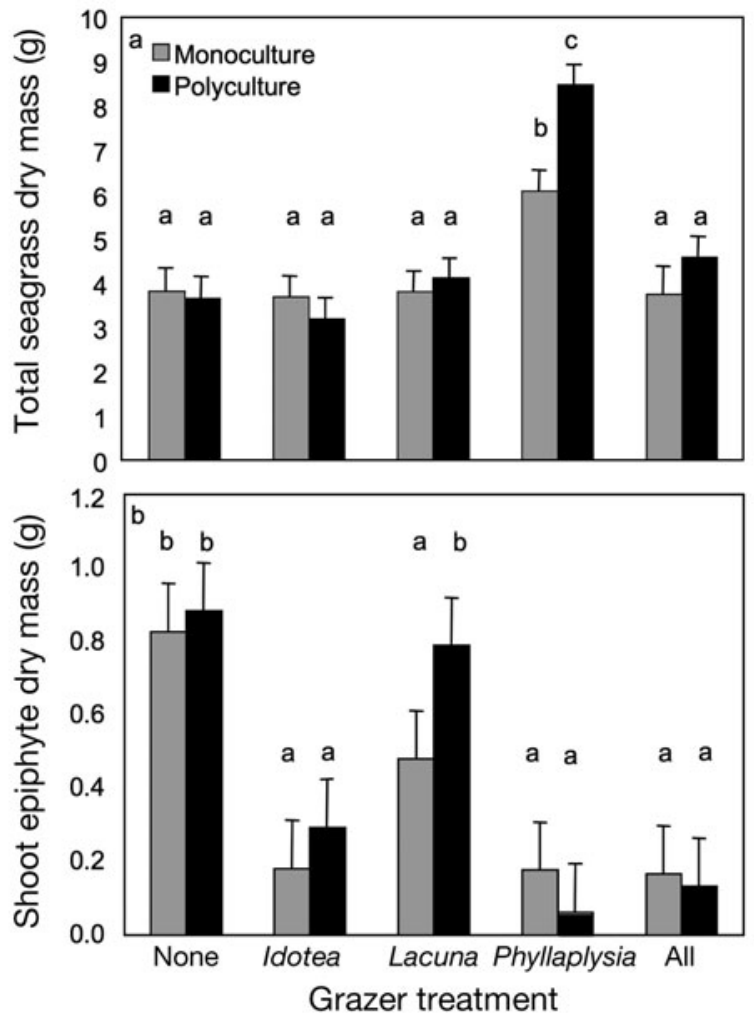

Fig. 1. Effects of grazer treatment and seagrass genotypic diversity on seagrass and epiphyte biomass. (a) Grazer identity and seagrass genotypic diversity interactively affect seagrass biomass. (b) Grazer identity affects epiphyte biomass. Statistical analysis by ANOVA. Letters indicate significant differences $(\mathrm{p}<0.05)$ according to Tukey's posthoc tests. Error bars represent $+1 \mathrm{SE}$

To understand better the mechanisms underlying the positive effect of genetic diversity in the presence of Phyllaplysia, we partitioned the biodiversity effect into 3 possible components (Fig. 3b) according to Fox (2005). TIC (equivalent to complementarity in the sense of Loreau \& Hector 2001) was generally strong and positive (Fig. 3b), meaning that genotypes generally had higher biomass in mixture than expected, regardless of absolute monoculture biomass. The strength of TIC was highly correlated $\left(\mathrm{R}^{2}=0.87, \mathrm{p}=\right.$ 0.007; Fig. 3c) with the variance in monoculture biomass of the component genotypes in each polyculture (which could indicate variation in growth strategies); trait-dependent complementarity and dominance showed no relationship ( $p>0.05$; Fig. 3c).

Both trait-dependent complementarity (TDC) and dominance (together equivalent to selection sensu Loreau \& Hector 2001) were negative but smaller in magnitude than TIC (Fig. 3b). This negative selection indicates a negative correlation between size in monoculture and relative increase in polyculture; it ap- 
Table 1. Results of statistical analyses for genotypic diversity and grazer treatment. Values in parentheses are df. Bold indicates significant effect at $\mathrm{p}<0.05$. Italics indicate most important effect based on the proportion of the variance explained $\left(\omega^{2}\right)$. MSE $=$ mean square error

\begin{tabular}{|c|c|c|c|c|c|c|c|c|}
\hline Factor & & $\begin{array}{l}\text { Seagrass } \\
\text { shoot } \\
\text { production }\end{array}$ & $\begin{array}{l}\text { Seagrass } \\
\text { biomass }\end{array}$ & $\begin{array}{c}\text { Seagrass } \\
\text { aboveground } \\
\text { biomass }\end{array}$ & $\begin{array}{l}\text { Seagrass } \\
\text { belowground } \\
\text { biomass }\end{array}$ & $\begin{array}{l}\text { Epiphyte } \\
\text { biomass }\end{array}$ & $\begin{array}{c}\text { Grazer } \\
\text { biomass }\end{array}$ & $\begin{array}{l}\text { Per capita } \\
\text { grazer } \\
\text { growth }\end{array}$ \\
\hline Block (2) & $\begin{array}{l}F \\
\mathrm{p} \\
\omega^{2}\end{array}$ & $\begin{array}{l}0.48 \\
0.62 \\
0.000\end{array}$ & $\begin{array}{l}0.63 \\
0.53 \\
0.000\end{array}$ & $\begin{array}{l}1.50 \\
0.24 \\
0.018\end{array}$ & $\begin{array}{l}0.42 \\
0.66 \\
0.000\end{array}$ & $\begin{array}{l}0.41 \\
0.67 \\
0.000\end{array}$ & $\begin{array}{l}8.25 \\
\mathbf{0 . 0 0 1} \\
0.125\end{array}$ & $\begin{array}{l}4.92 \\
\mathbf{0 . 0 1} \\
0.199\end{array}$ \\
\hline Genotypic diversity (1) & $\begin{array}{l}F \\
\mathrm{p} \\
\omega^{2}\end{array}$ & $\begin{array}{l}0.16 \\
0.69 \\
0.000\end{array}$ & $\begin{array}{l}3.17 \\
0.08 \\
0.019\end{array}$ & $\begin{array}{l}2.35 \\
0.13 \\
0.006\end{array}$ & $\begin{array}{l}2.08 \\
0.16 \\
0.002\end{array}$ & $\begin{array}{l}0.63 \\
0.44 \\
0.000\end{array}$ & $\begin{array}{l}0.06 \\
0.81 \\
0.000\end{array}$ & $\begin{array}{l}0.05 \\
0.82 \\
0.000\end{array}$ \\
\hline Grazer identity (4) & $\begin{array}{l}F \\
\mathrm{p} \\
\omega^{2}\end{array}$ & $\begin{array}{l}5.76 \\
\mathbf{0 . 0 0 1} \\
0.425\end{array}$ & $\begin{array}{l}22.17 \\
<\mathbf{0 . 0 0 1} \\
0.593\end{array}$ & $\begin{array}{r}14.75 \\
<\mathbf{0 . 0 0 1} \\
0.561\end{array}$ & $\begin{array}{r}18.25 \\
<\mathbf{0 . 0 0 1} \\
0.635\end{array}$ & $\begin{array}{r}12.29 \\
<\mathbf{0 . 0 0 1} \\
0.720\end{array}$ & $\begin{array}{r}29.75 \\
<\mathbf{0 . 0 0 1} \\
0.431\end{array}$ & $\begin{array}{l}1.61 \\
0.19 \\
0.119\end{array}$ \\
\hline $\begin{array}{l}\text { Block } \times \text { Genotypic } \\
\text { diversity (2) }\end{array}$ & $\begin{array}{l}F \\
\mathrm{p} \\
\omega^{2}\end{array}$ & $\begin{array}{l}1.10 \\
0.34 \\
0.005\end{array}$ & $\begin{array}{l}0.13 \\
0.88 \\
0.000\end{array}$ & $\begin{array}{l}0.37 \\
0.69 \\
0.000\end{array}$ & $\begin{array}{l}0.25 \\
0.78 \\
0.000\end{array}$ & $\begin{array}{l}1.76 \\
0.19 \\
0.039\end{array}$ & $\begin{array}{l}2.36 \\
0.11 \\
0.028\end{array}$ & $\begin{array}{l}2.37 \\
0.11 \\
0.07\end{array}$ \\
\hline Block $\times$ Grazer identity (8) & $\begin{array}{l}F \\
\mathrm{p} \\
\omega^{2}\end{array}$ & $\begin{array}{l}2.27 \\
\mathbf{0 . 0 5} \\
0.363\end{array}$ & $\begin{array}{l}0.57 \\
0.79 \\
0.044\end{array}$ & $\begin{array}{l}0.55 \\
0.81 \\
0.047\end{array}$ & $\begin{array}{l}1.03 \\
0.44 \\
0.118\end{array}$ & $\begin{array}{l}0.98 \\
0.47 \\
0.155\end{array}$ & $\begin{array}{l}3.18 \\
\mathbf{0 . 0 0 9} \\
0.194\end{array}$ & $\begin{array}{l}1.28 \\
0.29 \\
0.226\end{array}$ \\
\hline $\begin{array}{l}\text { Genotypic diversity } \times \\
\text { Grazer identity (4) }\end{array}$ & $\begin{array}{l}F \\
\mathrm{p} \\
\omega^{2}\end{array}$ & $\begin{array}{l}1.45 \\
0.24 \\
0.097\end{array}$ & $\begin{array}{l}3.08 \\
\mathbf{0 . 0 3} \\
0.149\end{array}$ & $\begin{array}{l}3.21 \\
\mathbf{0 . 0 3} \\
0.176\end{array}$ & $\begin{array}{l}0.87 \\
0.49 \\
0.029\end{array}$ & $\begin{array}{l}0.74 \\
0.57 \\
0.026\end{array}$ & $\begin{array}{l}2.74 \\
\mathbf{0 . 0 5} \\
0.086\end{array}$ & $\begin{array}{l}1.15 \\
0.35 \\
0.072\end{array}$ \\
\hline $\begin{array}{l}\text { Block } \times \text { Genotypic diversity } \\
\times \text { Grazer identity }(8)\end{array}$ & $\begin{array}{l}F \\
\mathrm{p} \\
\omega^{2}\end{array}$ & $\begin{array}{l}0.75 \\
0.64 \\
0.109\end{array}$ & $\begin{array}{l}1.92 \\
0.09 \\
0.195\end{array}$ & $\begin{array}{l}1.63 \\
0.16 \\
0.191\end{array}$ & $\begin{array}{l}1.82 \\
0.11 \\
0.216\end{array}$ & $\begin{array}{l}0.52 \\
0.83 \\
0.060\end{array}$ & $\begin{array}{l}2.06 \\
0.07 \\
0.136\end{array}$ & $\begin{array}{l}1.75 \\
0.13 \\
0.315\end{array}$ \\
\hline $\begin{array}{l}\text { Grazer polyculture vs. } \\
\text { monoculture contrast (1) }\end{array}$ & $\begin{array}{l}F \\
\mathrm{p}\end{array}$ & $\begin{array}{l}2.79 \\
0.10\end{array}$ & $\begin{array}{l}1.15 \\
0.29\end{array}$ & $\begin{array}{l}0.57 \\
0.45\end{array}$ & $\begin{array}{l}1.49 \\
0.23\end{array}$ & $\begin{array}{l}2.8 \\
0.10\end{array}$ & $\begin{array}{l}1.85 \\
0.18\end{array}$ & $\begin{array}{l}\text { NA } \\
\text { NA }\end{array}$ \\
\hline MSE (30) & & 2.55 & 1.27 & 0.83 & 0.18 & 0.11 & 0.36 & 0.01 \\
\hline
\end{tabular}

peared to result primarily from 3 genotypes that performed particularly poorly relative to others in seagrass monoculture with Phyllaplysia but had increased performance in seagrass polyculture with Phyllaplysia (Fig. 4). However, because there was only a single replicate of each genotypic monoculture for a given

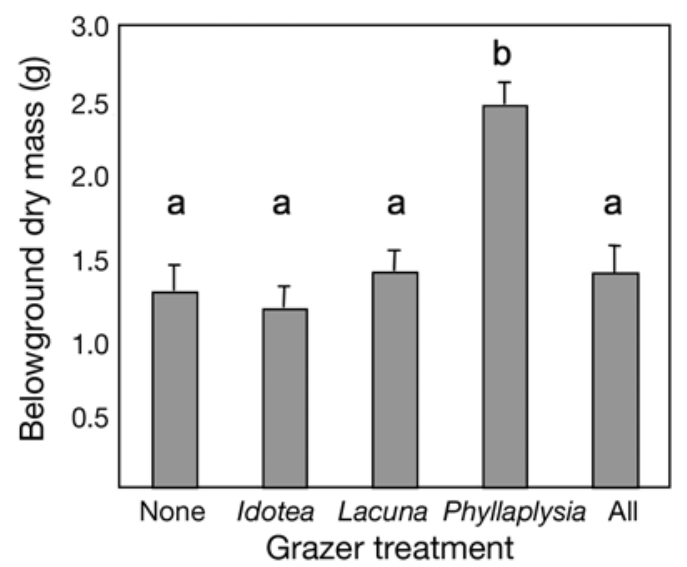

Fig. 2. Effects of grazer identity on seagrass belowground dry biomass. Statistical analysis by ANOVA. Letters indicate significant differences $(\mathrm{p}<0.05)$ according to Tukey's posthoc tests. Error bars represent $+1 \mathrm{SE}$ grazer treatment, it is impossible to rule out the contribution of factors other than genotype (i.e. environmental variation among mesocosms).

\section{Grazer response}

Final grazer biomass varied with seagrass genotypic diversity and grazer species identity (Table 1). However, final biomass was largely a function of initial biomass, which varied between grazer species. There was also an interaction between block and grazer species identity (Table 1). Per capita change in biomass did not differ from zero for any treatment (Table 1), indicating that the interactive effect of genotypic diversity and grazer identity was slight.

Grazer fecundity differed between grazer monoculture and grazer polyculture for both Idotea (Fig. 5a) and Lacuna (Fig. 5b), though in opposing directions. Idotea fecundity was greater in grazer polyculture than monoculture, whereas snail fecundity declined in polyculture. In contrast, production of Phyllaplysia egg cases was consistent across grazer treatments (Fig. 5c). Seagrass genotypic diversity did not affect grazer reproductive output either independently or interactively with grazer treatment. 

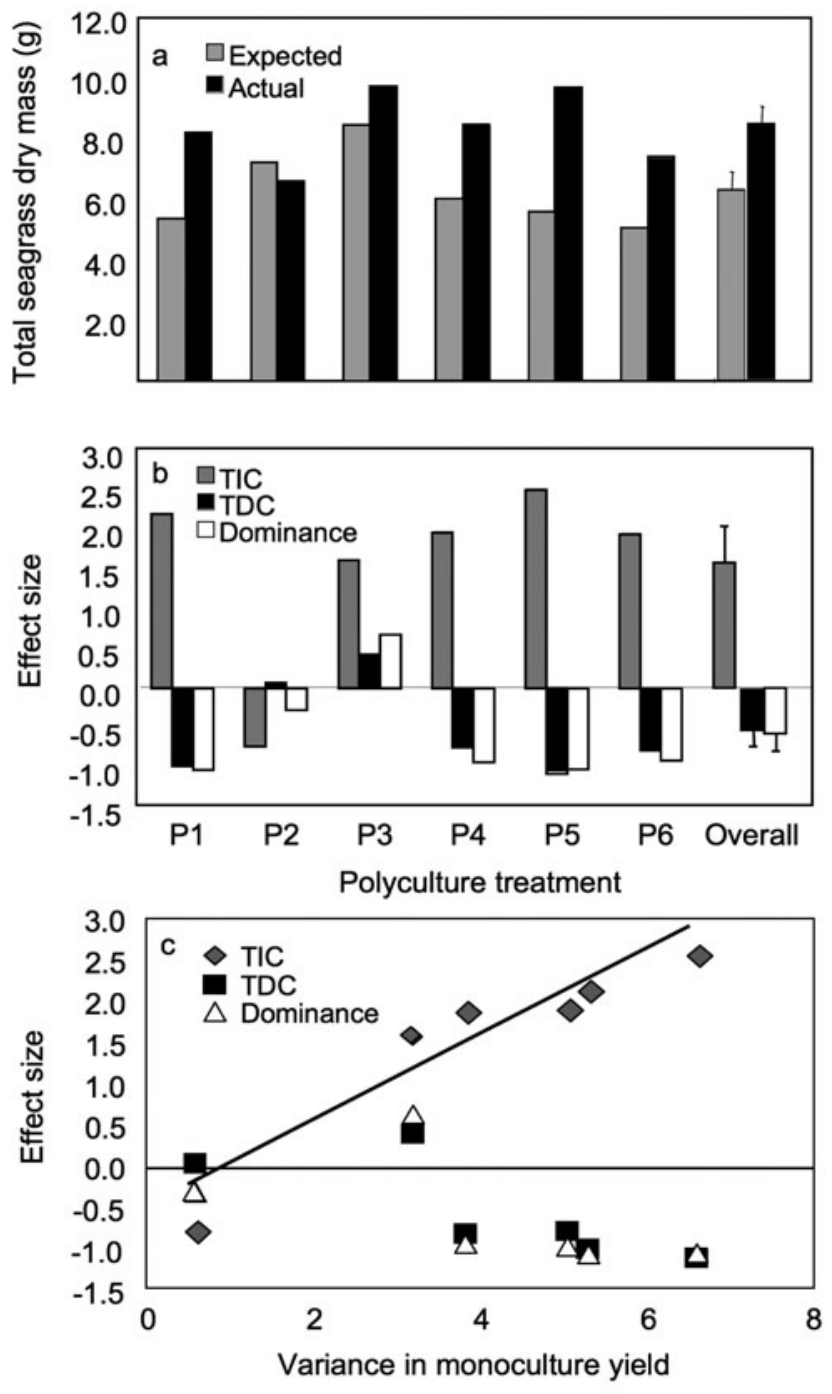

Fig. 3. Genotypic diversity mechanisms. (a) Actual versus expected seagrass polyculture biomass when grown with Phyllaplysia. Expected values are calculated based on the performance of component genotypes when grown in monoculture (see 'Materials and methods'). (b) Partitioning of the biodiversity effect into trait-independent complementarity (TIC), trait-dependent complementarity (TDC) and dominance. (c) Relationship between the variance in monoculture yield (as a proxy for phenotypic diversity) and the strength of TIC, TDC, and dominance. Effect sizes are square-root transformed with the original signs preserved as in Fox (2005). Error bars represent $+1 \mathrm{SE}$

\section{DISCUSSION}

Our experiment reinforces other findings (e.g. Williams 2001, Hughes \& Stachowicz 2004, 2009, Reusch et al. 2005) that positive effects of seagrass genetic diversity are contingent on specific abiotic or biotic conditions. As these previous experiments detected diversity effects in response to stress/distur-

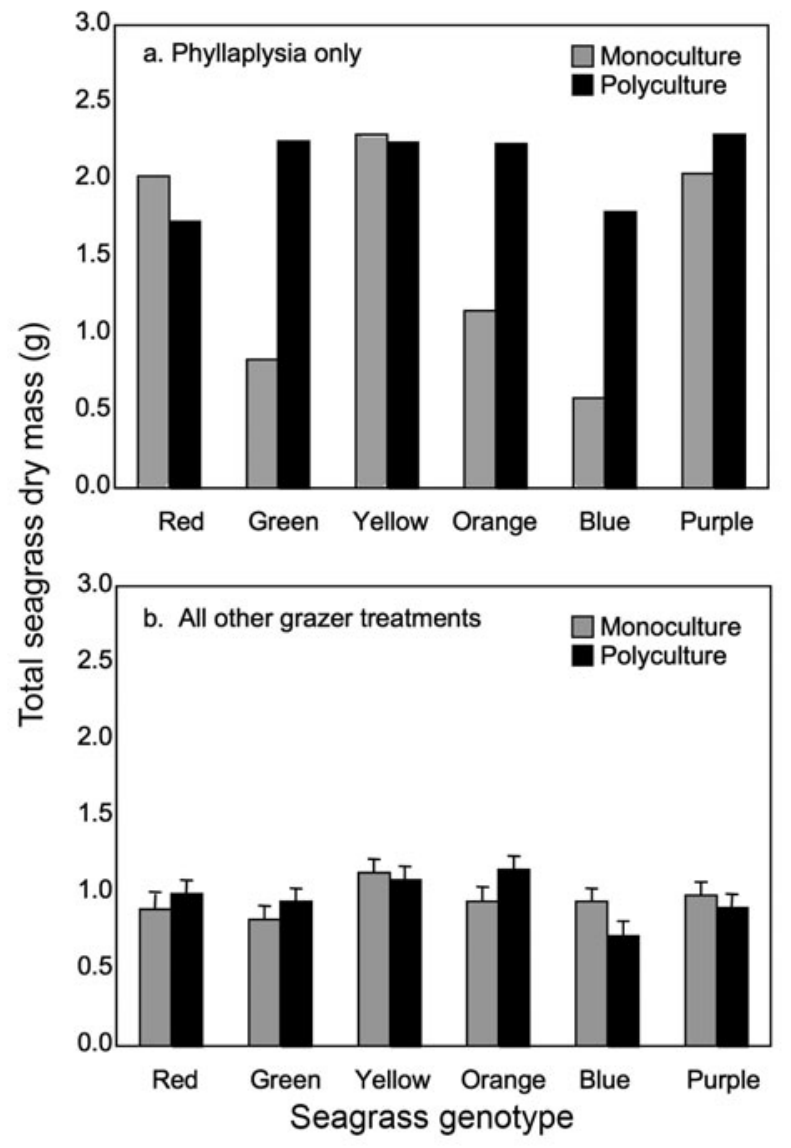

Fig. 4. Seagrass genotypic biomass per transplant in monoculture and polyculture. (a) Biomass of seagrass genotypes in the presence of Phyllaplysia only. Genotype color labels as in Hughes et al. (2009). (b) Biomass of seagrass genotypes in all other grazer treatments (no grazers, Idotea only, Lacuna only, and grazer polyculture)

bance, it is interesting that the positive impacts of genotypic diversity found here occur only in the Phyllaplysia treatment, in which the perceived 'stresses' (epiphyte biomass and direct seagrass grazing) were lowest. In this case, Phyllaplysia presence does lead to higher seagrass biomass overall as expected given the reduction in epiphyte biomass and direct grazing (Fig. 1), but this increase is greater in genotypic polyculture. Partitioning this diversity effect revealed that TIC (Fox 2005, complementarity sensu Loreau \& Hector 2001) was the dominant component of this effect (Fig. 3b). Complementary resource use could contribute to the increased growth in genotypic polyculture: because nutrient uptake rates and rooting depths are more similar among clonemates than non-clonemates (Hughes et al. 2009), it is likely that intra-genotypic competition for nutrients limits the growth of some genotypes in monoculture when total seagrass biomass is high. 

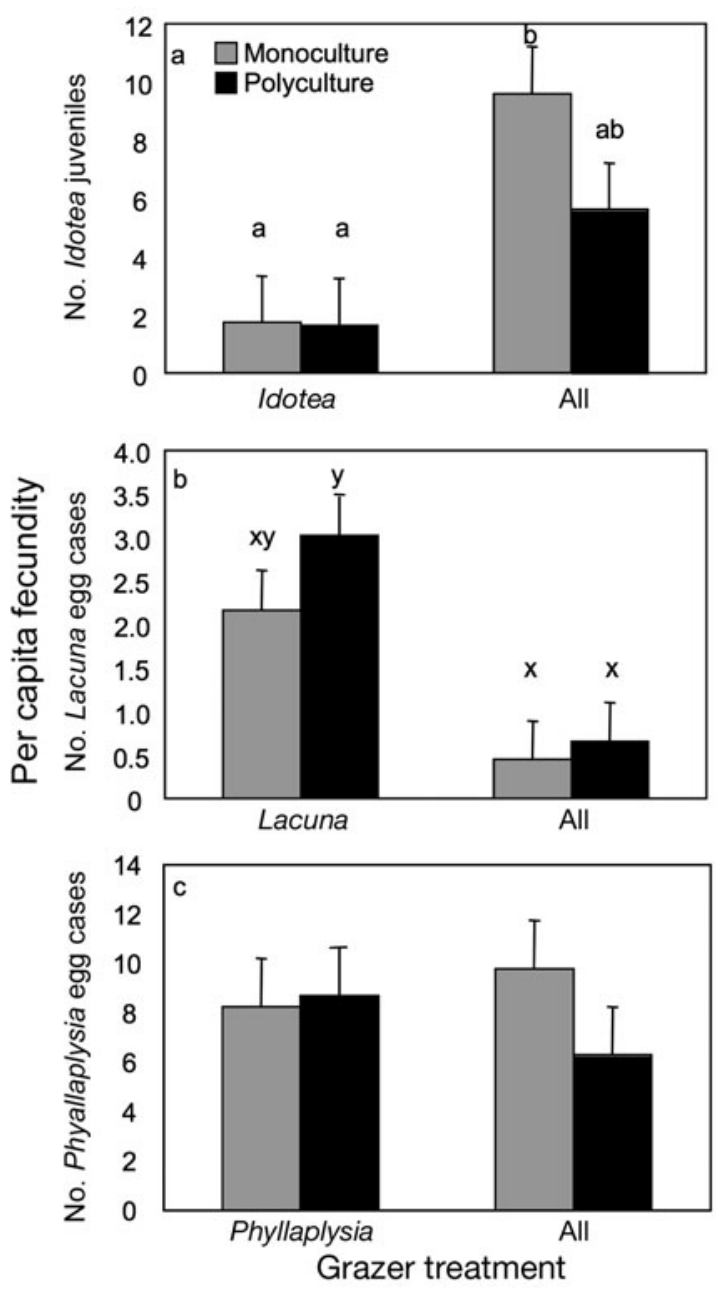

Fig. 5. Effects of seagrass genotypic diversity and grazer species diversity on per capita grazer reproductive effort. Data are presented as per capita because the initial number of grazers differed between grazer monoculture and grazer polyculture. (a) Number of newly produced juvenile Idotea. (b) Number of Lacuna egg cases. (c) Number of Phyllaplysia egg cases. Statistical analysis by ANOVA. Letters indicate significant differences ( $p<0.05)$ according to Tukey's posthoc tests. Error bars represent +1 SE

The positive TIC in polyculture was reduced by negative dominance and TDC (together equivalent to the selection effects of Loreau \& Hector 2001), because those genotypes least abundant in monoculture showed disproportionate increases in biomass in genotypic polyculture. Though negative, these effects were less consistent and weaker than those of TIC, resulting in a positive net diversity effect that was strongly affected by the combination of genotypes present in a polyculture, rather than just the presence of particular genotypes. Similar counteracting effects of complementarity and selection have been found in other seagrass genetic (Reusch et al. 2005) and algal species (Bruno et al. 2006) diversity experi- ments, though the net balance between these components varies among studies.

Seagrass genotypic diversity did not increase grazer reproductive output (Fig. 5), suggesting that the genotypes used are not complementary in nutritional content or secondary chemistry such that a benefit of a 'mixed' diet is realized for those species that directly consume seagrass (cf. Stachowicz et al. 2007). We did, however, find effects of grazer diversity on per capita reproductive effort (Fig. 5). Idotea reproduction was diminished in the monospecific treatment as compared to the grazer polyculture (Fig. 5a); such negative intraspecific effects could be due to either competition or cannibalism (Duffy et al. 2005). In contrast, Lacuna fecundity was reduced significantly by inter-specific interactions with Idotea and/or Phyllaplysia compared to when only snails were present (Fig. 5b). Because both Lacuna and Phyllaplysia utilize seagrass leaves for laying eggs, the larger Phyllaplysia egg cases may have preempted space needed by Lacuna. Phyllaplysia exhibited consistent reproductive effort regardless of grazer species diversity or seagrass genotypic diversity (Fig. 5c).

Overall, grazer identity was a key determinant of both epiphyte and seagrass biomass (Figs. 1 \& 2), in keeping with other grazer manipulations in similar systems (Duffy \& Harvilicz 2001, Duffy et al. 2001, 2003, 2005). Unlike some previous seagrass research (Duffy et al. 2003, 2005), we did not observe an effect of grazer species diversity on seagrass growth. The absence of such an effect could be the result of our experimental design (e.g. we tested a relatively small range in diversity; cf. Duffy et al. 2001 vs. Duffy et al. 2003; Stachowicz et al. 2007), yet it is also consistent with several key characteristics of this system. First, the diversity of epiphytic organisms on Zostera in our study system is relatively low, comprised mostly of diatoms and other microalgae, and relatively little macroalgae or fouling invertebrates (R. Hughes pers. obs.). Second, at least 2 of the dominant grazer species (Phyllaplysia and Idotea) are largely redundant in their ability to control these epiphytes, in that each alone can significantly reduce epiphyte biomass (Fig. 1b). Thus, there is little opportunity for complementarity among grazer species in their effects on epiphyte biomass, at least over the short term. However, variation in life history strategies (e.g. timing of reproduction) could result in important temporal diversity effects that have been demonstrated elsewhere (e.g. Stachowicz et al. 2002); studies of longer duration are needed to test for such effects in this system.

The importance of grazer identity (and not diversity) in this experiment likely stems from differences in feeding strategies among species, as has been shown in other mesograzer studies (Duffy \& Harvilicz 2001): 
whereas all of the species included in our experiment prefer to consume epiphytes, both Idotea and Lacuna/ Lirularia spp. will also consume seagrass (Williams \& Ruckelshaus 1993, R. Hughes unpubl. data). In this experiment, seagrass leaves in treatments with Idotea frequently showed evidence of grazing, with either holes or entire ends of blades missing. The tendency of Idotea to consume both epiphytes and seagrasses may explain why seagrass biomass did not increase in the presence of Idotea, despite reduced epiphyte biomass. In contrast, equivalently low epiphyte biomass was associated with significantly higher seagrass biomass in the presence of Phyllaplysia alone. Consumption of seagrass by Idotea when epiphyte biomass is low may also explain the absence of a seagrass response to grazer polyculture, despite the presence of Phyllaplysia. Alternatively, the positive effect of Phyllaplysia on seagrass biomass may be absent in grazer polyculture because of lowered Phyllaplysia densities in these treatments due to our substitutive experimental design. Overall, our results highlight that although the effects of individual grazer species vary, collectively grazers exhibit strong top-down control of epiphyte biomass.

Our mesocosms did not include predators of grazers, so we did not test the possibility that increased refuge (e.g. due to higher shoot density or biomass) would lead to greater abundance or biomass of grazers in seagrass polycultures. Differential susceptibility to or tolerance of predation among grazer species could also lead to grazer species diversity effects that were not tested for here (e.g. Duffy et al. 2005). Further studies including higher trophic levels are needed to test additional mechanisms by which seagrass genotypic identity/diversity and grazer species diversity interact to influence seagrass communities.

This study was motivated by a lack of information regarding the reciprocal effects of diversity at multiple trophic levels. Although there was no interaction between grazer species diversity and seagrass genotypic diversity in our experiment, the effects of genotypic diversity on overall seagrass and grazer biomass did vary depending on the grazer species present. This result underscores the need to consider multiple trophic levels in diversity manipulations, as has been stressed by others (Duffy et al. 2007). Further, it confirms that genotypic diversity as well as identity can be important for key population- and community-level parameters such as seagrass and grazer biomass. Given the predominance in marine systems of habitat-providing species similar to seagrasses (e.g. kelps, corals, salt marsh grasses), the strong role of consumer control of producer biomass (Paine 2002), as well as changes in consumer abundance and diversity in these systems (Jackson et al. 2001, Duffy 2002, Byrnes et al. 2007), the phenomena we describe here may be widespread.
Acknowledgements. We thank J. Abbott, K. Aquilino, A. Chaudoin, G. Crutsinger, and K. Edwards for help with the experiment. Critical comments by K. Heck and 4 anonymous reviewers greatly improved the manuscript. This work was supported by NSF grant OCE-06-23641 to J.J.S. and A.R.H.

\section{LITERATURE CITED}

Aquilino KM, Cardinale BJ, Ives AR (2005) Reciprocal effects of host plant and natural enemy diversity on herbivore suppression: an empirical study of a model tritrophic system. Oikos 108:275-282

Balvanera P, Pfisterer AB, Buchmann N, He JS, Nakashizuka T, Raffaelli D, Schmid B (2006) Quantifying the evidence for biodiversity effects on ecosystem functioning and services. Ecol Lett 9:1146-1156

> Bruno JF, Cardinale BJ (2008) Cascading effects of predator richness. Front Ecol Environ 6:539-546

Bruno JF, Lee SC, Kertesz JS, Carpenter RC, Long ZT, Duffy JE (2006) Partitioning the effects of algal species identity and richness on benthic marine primary production. Oikos 115:170-178

Bruno JF, Boyer KE, Duffy JE, Lee SC (2008) Relative and interactive effects of plant and grazer richness in a benthic marine community. Ecology 89:2518-2528

Byrnes J, Stachowicz JJ, Hultgren KM, Hughes AR, Olyarnik SV, Thornber CS (2006) Predator diversity strengthens trophic cascades in kelp forests by modifying herbivore behavior. Ecol Lett 9:61-71

Byrnes JE, Reynolds PL, Stachowicz JJ (2007) Invasions and extinctions reshape coastal marine food webs. PLoS One 2:e295

> Cardinale BJ, Wright JP, Cadotte MW, Carroll IT and others (2007) Impacts of plant diversity on biomass production increase through time because of species complementarity. Proc Natl Acad Sci USA 104:18123-18128

> Crawford KM, Crutsinger GM, Sanders NJ (2007) Genotypic diversity mediates the distribution of an ecosystem engineer. Ecology 88:2114-2120

Crutsinger GM, Collins MD, Fordyce JA, Gompert Z, Nice CC, Sanders NJ (2006) Plant genotypic diversity predicts community structure and governs an ecosystem process. Science 313:966-968

Douglass JG, Duffy JE, Bruno JF (2008) Herbivore and predator diversity interactively affect ecosystem properties in an experimental marine community. Ecol Lett 11:598-608

> Duffy JE (2002) Biodiversity and ecosystem function: the consumer connection. Oikos 99:201-219

$>$ Duffy JE, Harvilicz AM (2001) Species-specific impacts of grazing amphipods in an eelgrass bed community. Mar Ecol Prog Ser 223:201-211

Duffy JE, Macdonald KS, Rhode JM, Parker JD (2001) Grazer diversity, functional redundancy, and productivity in seagrass beds: an experimental test. Ecology 82:2417-2434

Duffy JE, Richardson JP, Canuel EA (2003) Grazer diversity effects on ecosystem functioning in seagrass beds. Ecol Lett 6:637-645

$>$ Duffy JE, Richardson JP, France KE (2005) Ecosystem consequences of diversity depend on food chain length in estuarine vegetation. Ecol Lett 8:301-309

> Duffy JE, Cardinale BJ, France KE, McIntyre PJ, Thebault E, Loreau M (2007) The functional role of biodiversity in ecosystems: incorporating trophic complexity. Ecol Lett 10:522-538

> Fox JW (2004) Effects of algal and herbivore diversity on the partitioning of biomass within and among trophic levels. 
Ecology 85:549-559

Fox JW (2005) Interpreting the 'selection effect' of biodiversity on ecosystem function. Ecol Lett 8:846-856

> Gamfeldt L, Hillebrand H, Jonsson PR (2005) Species richness changes across two trophic levels simultaneously affect prey and consumer biomass. Ecol Lett 8:696-703

$>$ Hairston NG, Smith FE, Slobodkin LB (1960) Community structure, population control and competition. Am Nat 94:421-425

Hughes AR, Stachowicz JJ (2004) Genetic diversity enhances the resistance of a seagrass ecosystem to disturbance. Proc Natl Acad Sci USA 101:8998-9002

Hughes AR, Stachowicz JJ (2009) Ecological impacts of genotypic diversity in the clonal seagrass Zostera marina. Ecology 90:1412-1419

> Hughes AR, Bando KJ, Rodriguez LF, Williams SL (2004) Relative effects of grazers and nutrients on seagrasses: a meta-analysis approach. Mar Ecol Prog Ser 282:87-99

Hughes AR, Inouye BD, Johnson MTJ, Vellend M, Underwood N (2008) Ecological consequences of genetic diversity. Ecol Lett 11:609-623

Hughes AR, Stachowicz JJ, Williams SL (2009) Morphological and physiological variation among seagrass (Zostera marina) genotypes. Oecologia 159:725-733

Jackson JBC, Kirby MX, Berger WH, Bjorndal KA and others (2001) Historical overfishing and the recent collapse of coastal ecosystems. Science 293:629-638

Johnson MTJ, Lajeunesse MJ, Agrawal AA (2006) Additive and interactive effects of plant genotypic diversity on arthropod communities and plant fitness. Ecol Lett 9: 24-34

Loreau M, Hector A (2001) Partitioning selection and comple-

Editorial responsibility: Kenneth Heck Jr.,

Dauphin Island, Alabama, USA mentarity in biodiversity experiments. Nature 412:72-76

Lubchenco J (1978) Plant species diversity in a marine intertidal community: importance of herbivore food preference and algal competitive abilities. Am Nat 112:23-39

> Olejnik S, Algina J (2003) Generalized eta and omega squared statistics: Measures of effect size for some common research designs. Psychol Methods 8:434-447

Orth RJ, Carruthers TJB, Dennison WC, Duarte CM and others (2006) A global crisis for seagrass ecosystems. Bioscience 56:987-996

Paine RT (2002) Trophic control of production in a rocky intertidal community. Science 296:736-739

> Reusch TBH, Ehlers A, Haemmerli A, Worm B (2005) Ecosystem recovery after climatic extremes enhanced by genotypic diversity. Proc Natl Acad Sci USA 102:2826-2831

Schmitz OJ, Hamback PA, Beckerman AP (2000) Trophic cascades in terrestrial systems: a review of the effects of carnivore removals on plants. Am Nat 155:141-153

Stachowicz JJ, Fried H, Osman RW, Whitlatch RB (2002) Biodiversity, invasion resistance, and marine ecosystem function: reconciling pattern and process. Ecology 83: $2575-2590$

Stachowicz JJ, Bruno JF, Duffy JE (2007) Understanding the effects of marine biodiversity on communities and ecosystems. Annu Rev Ecol Evol Syst 38:739-766

Williams SL (2001) Reduced genetic diversity in eelgrass transplantations affects both population growth and individual fitness. Ecol Appl 11:1472-1488

Williams SL, Ruckelshaus MH (1993) Effects of nitrogen availability and herbivory on eelgrass (Zostera marina) and epiphytes. Ecology 74:904-918

Submitted: July 22, 2009; Accepted: January 20, 2010

Proofs received from author(s): March 4, 2010 